\title{
Adaptation to Climate Change: Status, Household Strategies and Challenges in Lesotho
}

\author{
Kheleli Mareabetsoe Rethabile*1, Zhang Jing2, Tsepang Clementine \\ Mofolo $^{1}$ and Edmore Mwandiringana ${ }^{3}$
}

\author{
${ }^{1}$ UN Environment-Tongji Institute of Environment for Sustainable Development \\ College of Environmental Science and Engineering, Tongji University \\ 1239 Siping Road, Shanghai 200092, China \\ ${ }^{2}$ College of Environmental Science and Engineering, Tongji University \\ 1239 Siping Road, Shanghai 200092, China
${ }^{3}$ College of Humanities and Development, China Agricultural University Qinghua E Rd, Haidian District, Beijing, China
Email: Kheleli.marea@gmail.com; jingzhang@tongji.edu.cn; tsepangmofolo13@gmail.com; easymwa@yahoo.co.uk

*Corresponding author details: Kheleli M. Rethabile; Kheleli.marea@gmail.com

\begin{abstract}
Rural livelihoods across Lesotho have been markedly impacted by climate change, as they are largely agriculture dependent (80\%). Adaptation to the events of climate variability especially in agriculturally dependent communities is of importance. In drier districts given the fact that agriculture is the most affected sector, the (Lesotho) state adopted several strategies and measures for climate change adaptation to improve rural livelihoods. To get an overview of adaptation, the study reviewed the National Adaptation Programme Actions (NAPA), Nationally Determined Contributions (NDCs) and the National Policy on Climate Change (NPCC) as the instruments specific to adaptation to climate change. A case study of Mafeteng district, an area subjected to persistent drought events was selected to examine adaptation strategies employed. Two prominent strategies highlighted in the study are conservation agriculture and keyhole gardening. Furthermore, a top down approach is found to exist in terms of adaptation planning, not only that but adaptation action is more focused on capacity building of technocrats whilst households are struggling to adapt at grassroots level. Secondly, research is limited to national assessments leading to nonspecific interventions and last adaptation projects are largely donor funded lacking sustainability in turn. This therefore warrants integrated planning and an interdependent stakeholder approach is proposed as a way forward.
\end{abstract}

Keywords: climate change; adaptation; legal instruments; household strategies

\section{INTRODUCTION}

With the changing climate around the globe there is urgent need to address climate change which if not urgently attended to, will continue to negatively impact biota and ecosystems. Humans in different parts of the globe are already experiencing greater warming that is above the globes averages, the higher averages are seen to be increasing in land areas at a faster rate while in oceans the warming rate is reported to be slower ${ }^{1}$. Observed temperature changes can be attributed to the release of GHGs as a result of burning of fossil fuels especially in the industrialized world ${ }^{2}$.

The effects of climate change are evident in deteriorating health conditions, food insecurity, loss of economic stability and out-migration leading to erosion of culture ${ }^{3,4}$. It is estimated that there will be a $50 \%$ reduction in agricultural production in some countries in Africa by 2020 and a $90 \%$ net crop revenue drop set to affect mostly small scale agriculture 5 . Water security due to recurring droughts is also set to affect most African countries. Temperature increases are also bound to be higher in the sub-Saharan Africa region than the Worlds' average due to the anticipated decline in the amount of rainfall 6 .

The vulnerability of sub-Saharan Africa to climate change can largely be attributed to the exceedingly low adaptive capacity that is linked to poor infrastructure and severe poverty $^{7-9}$. Lesotho as a country is not immune to the vulnerability faced by other countries in the region. Over $80 \%$ of the country's population resides in the rural areas and relies heavily on rain fed (subsistence) agriculture ${ }^{10}$. The socio-economic vulnerability is often intertwined with 
biophysical vulnerability of the population that already has few livelihood options. Under the projected climate changes, $15 \%$ of the currently moderate vulnerable households will move to high vulnerability ${ }^{11}$. This therefore warrants the adoption of sustainable adaptation strategies for improved livelihoods which are already stressed and are expected to deteriorate further unless viable interventions are implemented.

As climate variability goes unabated, households have become increasingly vulnerable to the impacts of climate change. Vulnerability to climate change is defined by IPCC as;

\begin{abstract}
"the degree, to which a system is susceptible to, or unable to cope with the adverse effects of climate change, including variability and extremes. Vulnerability is seen as a function of character, magnitude and rate of climate variation to which a system is exposed, its sensitivity and its adaptive capacity" 12 .
\end{abstract}

The fourth IPCC assessment report recognizes the importance of adaptation while mitigation efforts are being planned and rolled out. Adaptation is therefore defined as "the adjustment in a natural or human system in response to the actual expected climate stimuli or their effects, with moderate, harm or exploit beneficial opportunities"12. The implication is that to adapt is therefore recognized as an integral part in the climate change discourse around the globe that needs states' attention.

This study examines the status of climate change adaptation in Lesotho. It analyzes existing adaptation instruments, use of a case study for agricultural adaptation strategies for climate change in Mafeteng households and also a discussion of main adaptation challenges based on the analysis. The study is based on the assumption that an understanding of the status quo (of climate change adaptation) will lead to effective policy formulation and implementation at all levels of the community.

\section{STUDY AREA}

Lesotho consists of four livelihood zones namely the Senqu river valley, mountains, lowlands and foothills as depicted in figure 1.

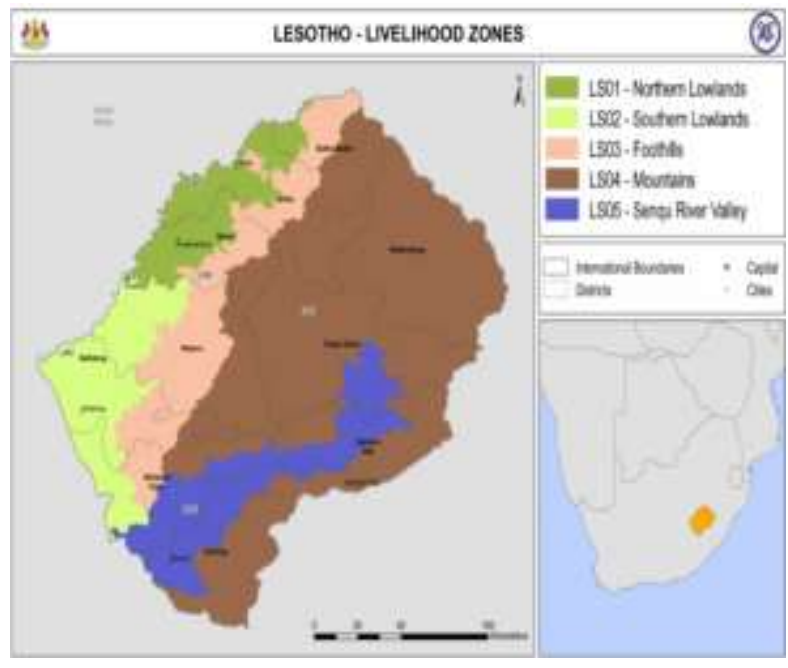

FIGURE 1: Lesotho livelihood zones ${ }^{13}$

Lesotho is landlocked with the population that is predominantly $(80 \%)$ rural. Most of these rural dwellers are small scale farmers who rely exclusively on rain for their agricultural praxis ${ }^{3}$. The Poverty that is mainly characterized by food insecurity and largely linked to climate change is rife, and recurring droughts have a far- reaching impact to the already vulnerable rural livelihoods. Also, there is lack of appropriate infrastructure to absorb the shocks that result from harsh weather extremities 3.60 to $70 \%$ of the rural dwellers are engaged in the agricultural sector which contributes about $7.4 \%$ of the country's GDP of Lesotho ${ }^{14,15}$, that has declined from $25 \%$ in the 1980 's ${ }^{16}$.

Three quarters of the rural smallholder farmers to the total rural population contribute about $30 \%$ of the total agricultural output in the country ${ }^{17}$. This agriculture is characterized by low input and low cereal crop output ${ }^{15}$. However, this sector faces a threat from recurrent droughts and wide spread land degradation. Similarly, most of the rural smallholder farmers are poor thereby lacking the capability as well as assets to cope with the adverse effects of climate change ${ }^{18}$. Poor soil quality, decreased land acreage due to soil erosion and labor constraints are some of the challenges facing smallholder farmers in Lesotho, thereby affecting the sustainability of agriculture as a viable livelihood option ${ }^{19}$. For instance, between October 2019 and March 2020, 30\% of rural households (about 433,000 people) were in need of (food) assistance ${ }^{20}$. This calls for a need to formulate and implement viable livelihood strategies supported by legal instruments to deal with the effects of climate change.

Lesotho's economy is based mainly on four sectors of water, manufacturing, agriculture and mining ${ }^{10}$. Two of these sectors (agriculture and water) are highly affected by climate change. Climate change does not only impact socioeconomic activities, but ecosystems and the water dependent life forms. An impact on the water sector does not only affect Lesotho but other countries in the region as Lesotho forms a major source of fresh water for South Africa, Namibia and Botswana ${ }^{16}$

\section{CLIMATE CHANGE ADAPTATION INSTRUMENTS}

As a member state of Southern African Development Countries (SADC), Lesotho ratified the UNFCCC in 1995 and signed the Kyoto Protocol which emphasized the need to reduce the impacts of global warming and adapting to climate variability21. The State has therefore adopted policy and programmes aimed at meeting the goals of the ratified protocols.

\section{Lesotho's National Programme Adaptation of Action (NAPA)}

The NAPA was formulated in 2006 with a view to meet the requirements of the UNFCCC and Kyoto protocol ratified in 2000. NAPA aims to mainstream actions in the development planning process 22 so as to deal with the impacts of climate change. Under NAPA, the State identifies vulnerable communities and comes up with livelihood strategies to alleviate the effects of climate change. A list of activities that are core to the programme of action is then drawn up and priorities for capacity building identified ${ }^{23}$. Table 1 shows the list of adaptation projects identified by the State in order of priority ${ }^{23}$. Since adoption of NAPA, the State has since demarcated Lesotho into three vulnerability zones; i. Southern Lowlands across the Senqu River Valley (Most vulnerable) ii. Mountainous areas and iii. Northern Lowlands and foothills (least vulnerable) ${ }^{23}$. The Southern Lowlands (most vulnerable zone) is under tremendous environmental stress and highly threatened by climate change. It is inhabited by peasant (subsistence) farmers and small livestock farmers who have limited livelihood options in view of climate change. On the other hand, the mountains zone has minimal agricultural land due to its terrain thus presenting critical vulnerability. The third zone (Northern Lowlands and foothills) is exposed to climate change risk as it is prone to drought yet there is great dependency of livelihoods to farming 23 . 
TABLE 1: NAPA prioritized adaptation options projects ${ }^{23}$

\begin{tabular}{|c|c|}
\hline OPTION & Project Title \\
\hline 1 & $\begin{array}{l}\text { Improve Resilience of Livestock Production Systems Under Extreme Climatic Conditions in } \\
\text { Various Livelihood Zones in Lesotho }\end{array}$ \\
\hline 2 & $\begin{array}{l}\text { Promoting Sustainable Crop Based Livelihood Systems in Foothills, Lowlands and Senqu River } \\
\text { Valley Option }\end{array}$ \\
\hline 3 & $\begin{array}{l}\text { Capacity Building and Policy Reform to Integrate Climate Change in Sectoral Development } \\
\text { Plans Option }\end{array}$ \\
\hline 4 & Improvement of an Early Warning System Against Climate Induced Disasters and Hazards \\
\hline 5 & Securing Village Water Supply for Communities in the Southern Lowlands \\
\hline 6 & $\begin{array}{l}\text { Management and Reclamation of Degraded and Eroded Land in the Flood Prone Areas (Pilot } \\
\text { Project for Western Lowlands) }\end{array}$ \\
\hline 7 & Conservation and Rehabilitation of Degraded Wetlands in the Mountain Areas of Lesotho \\
\hline 8 & $\begin{array}{l}\text { Improvement of Community Food Security Through the Promotion of Food Processing and } \\
\text { Preservation Technologies }\end{array}$ \\
\hline 9 & Strengthening and stabilizing eco-tourism based rural livelihoods \\
\hline 10 & Promote Wind, Solar and Biogas Energy Use as a Supplement to Hydropower Energy \\
\hline 11 & $\begin{array}{l}\text { Stabilizing Community Livelihoods which are Adversely Affected by Climate Change Through } \\
\text { Improvement of Small Scale Industries }\end{array}$ \\
\hline
\end{tabular}

$36 \%$ of the identified adaptation projects fall under agriculture followed by water at $18 \%$ and other adaptation projects accounting for $9 \% 22$. It becomes evident therefore that agriculture is essential in climate adaptation. However, there is need for capacity building in order to integrate the adaptation projects into the national plans and subsequently implement them to enable climate change adaptation ${ }^{22}$.

\section{Nationally Determined Contributions}

The Nationally Determined Contributions adopted in 2017 focus on the implementation of integrated adaptation solutions that promote cost effective energy efficiency and cleaner production. This is the country's effort to replace fossil fuels commonly used in rural areas of the country and also to forego importation of electricity from neighboring South Africa through hydropower plants development. It emphasizes the creation of synergies between climate change adaptation and mitigation in a manner that is socially, environmentally and economically sound 16 . However, the country faces various challenges against the attainment of effective adaptation. These include poor infrastructure, poverty and health related challenges such as HIV/AIDS24.

\section{Climate Change Policy}

Although the State ratified the UNFCCC in 1995 and signed the Kyoto Protocol in 2000 it was not until 2017 that the Climate Change Policy was promulgated. The Policy was meant to enable the coordination of various initiatives for climate change adaptation. It was also designed to mainstream and facilitate the implementation of appropriate adaptation strategies across different sectors as a means to tackle climate change impacts ${ }^{25}$. This is envisaged to be done in three levels namely policy, national and local. The Policy is composed of five core pillars namely adaptation and climate risk reduction, mitigation and low-carbon development promotion, governance and institutional arrangements, climate finance and investment framework and also cross cutting issues (such as capacity building, public awareness, research) ${ }^{25}$

\section{ADAPTATION STRATEGIES: \\ A CASE STUDY ON MAFETENG}

One of the driest districts in Lesotho is Mafeteng ${ }^{26}$ situated south of the capital city Maseru. Mafeteng is home to 178,222 inhabitants ${ }^{10}$, falling under the southern lowlands zone which is the most vulnerable to climate change in the country. Frequently hit by droughts 3 , the population has largely been vulnerable to the impacts of climate change ${ }^{23}$, 26,27 . The southern district is subject to recurring droughts coupled with high land degradation score ${ }^{28}$ which have disturbed the livelihoods of the inhabitants. The 2015-16 El Nino oscillation event, classified as the worst since 1985 hit Mafeteng so hard that the World Food Programme (WFP) introduced an immediate response emergency operation which was meant to target around 4,184 households in the southern districts of Mohale's Hoek and Mafeteng29.

The district is characterized by monoculture and conventional tillage farming practices, which have proven to be less productive due to climate variability. One study in Mafeteng showed that the effects brought about by climate change according to farmers include reduced yield (40\%), droughts and floods (23\%), soil erosion (17\%), poor crop quality $(16 \%)$ and less prominent shortened seasons $(4 \%)^{30}$. These results are a clear indication of a need to adapt and there have been interventions to assist farmers to cope.

\section{Household agricultural adaptation strategies}

The state in collaboration with non-state actors has introduced a number of interventions that are inclusive of cash transfers, agricultural input subsidies and most importantly adaptation strategies that include conservation agriculture and keyhole gardens ${ }^{30}$. The two strategies are elaborated in the text that follows. These strategies have been promoted under the banner of environmental protection and improvement of livelihoods ${ }^{31}$

\section{- Keyhole gardening}

Keyhole gardening was introduced by C-safe (Consortium for Southern Africa Food Security Emergency) a project by CARE, 
World Vision and Catholic Relief Services in collaboration with the ministry of agriculture and food security in Lesotho ${ }^{32}$. A keyhole garden is "a round raised garden made with layers of soil, ash manure organic matter supported with stones"33. Key opportunities include high productivity, low maintenance, low labor, material for construction are sourced locally and it further strengthens social networks thus enhancing the ability of community in dealing with other development problems ${ }^{33}$. The keyhole gardens are meant to improve nutrition and build climate resilience ${ }^{3}$, making it a good strategy for the drought prone area as it provides vegetable all year to feed a household 30 . In a study in Mafeteng, results indicated that $80 \%$ of the households have adopted keyhole gardening as strategy against climate change impacts ${ }^{30}$.

\section{- Conservation agriculture}

Several African countries including Lesotho have adopted Conservation agriculture (CA). Local farmers have adapted the Likotjana (holes) practice which is argued to enhance soil fertility and also minimize soil erosion 34,35 . This practice has 3 principles of intercropping and crop rotation, minimal tillage and soil disturbance as well as soil cover through live mulching and crop residues ${ }^{36}$. CA is a concept for a resource saving agricultural crop production that strives to achieve acceptable profits together with high and sustained production levels while conserving the environment 37 .

Although CA as an agricultural system is said to be labor intensive, it is also argued to retain moisture more, control soil erosion and also enhance soil fertility as opposed to conventional agriculture ${ }^{30}$. Even though conventional farming was argued to yield more output ${ }^{30}$, in the event of a drought season it would mean vulnerability is increased while conservation agriculture would mean sustained yield for food security ${ }^{26}$. A number of farmers argue that they are not undertaking CA because it is too labor intensive ${ }^{30}$. With the droughts in Mafeteng, this type of farming can be more beneficial if accepted holistically by farmers, hence making households resilient to the impacts of climate change.

\section{CLIMATE CHANGE ADAPTATION CHALLENGES}

\section{Institutional top down approach}

The institutional top down approach creates a difficulty in adaptation and implementation as people do not have a sense of ownership. Such an approach results in institutional complexities during implementation at local level (community or household level) ${ }^{38}$. The top down perspective has also failed when used by donor agencies. Whenever the donor projects come to an end, interventions are usually dropped by the beneficiaries ${ }^{14}$. The approach is also an inhibiting factor to adoption as grassroots experiences are not incorporated into adaptation planning. Therefore, a bottom up strategy would be ideal as it considers present and past vulnerabilities ${ }^{39}$.

\section{Donor financial support reliance}

Relatedly, all interventions identified under NAPA and the NDC are reliant on donor financial support, not only these, also the adaptation strategies discussed are non-state and United Nations funded. This therefore starves locally developed adaptation options of the necessary financial capital for implementation, thus hindering full acceptance of new approaches by intended beneficiaries. The strategies employed for adaptation are later abandoned by beneficiaries leading to an unsustainable solution to the impacts of climate change. Apart from the top-down approach, traditional challenges such as poverty and HIV/AIDS also affect implementation.

\section{Lack of capacity and research for adaptation}

NAPA correctly identifies capacity building as an essential component of climate change adaptation, much of the financial capital is spent on equipping technocrats with skills while the grassroots dwellers are further being impacted by climate change. However, the adaptive capacity of intended beneficiaries (households) is crucial to intervention efforts ${ }^{40}$ but only few literature or data exists for this assessment ${ }^{20}, 27,41$. Monitoring and evaluation of interventions for further honing of the adaptation responses is also affected by lack of capacity to plan for adaptation. Thus, making it difficult to measure the success of employed strategies or adjust and refine them for better results, this further impedes adaptation to climate change for households.

\section{AN INTERGRATED STAKEHOLDER APPROACH TO ADAPATATION PLANNING}

While NAPA identifies the impacts of climate change, the Nationally Determined Contributions offer solutions that can enhance adaptation. The Climate Change Policy "envisions to build climate change resilience and lowcarbon pathways including a prosperous sustainable economy and environment in Lesotho" 25 . However, there is lack of synergy between the science behind climate change and actual happenings on the ground. Furthermore, decentralization on climate change issues still lacks as local level committees are yet to be formed, this is three years after the promulgation of the policy which clearly articulates the institutional structure of the policy that includes the said committees.

Collaboration of all actors including institutions of higher learning, government departments, non-state actors and the general public at grass-root level is necessary if the country is to win against the adverse impacts of climate change on household livelihoods. Therefore, a more integrated approach for adaptation planning is essential. Government departments need to budget and include adaptation to climate change in their annual plans to enhance service delivery in the climate change era. Not only this, the plans should be reflective of grassroots needs through public participation and involvement. Research is also an integral part of the planning process where institutions of higher learning need to study adaptation options and make sound recommendations that should be incorporated in the planning process.

As a developing country, Lesotho lacks the necessary resources for climate change adaptation hence the need to rope in development partners to provide technical and financial assistance is a given. This calls for need for the engagement of non-state actors with a view to mobilize financial resources to support interventions that are locally driven for sustainable development. An integrated stakeholder planning approach is therefore proposed in figure 2.

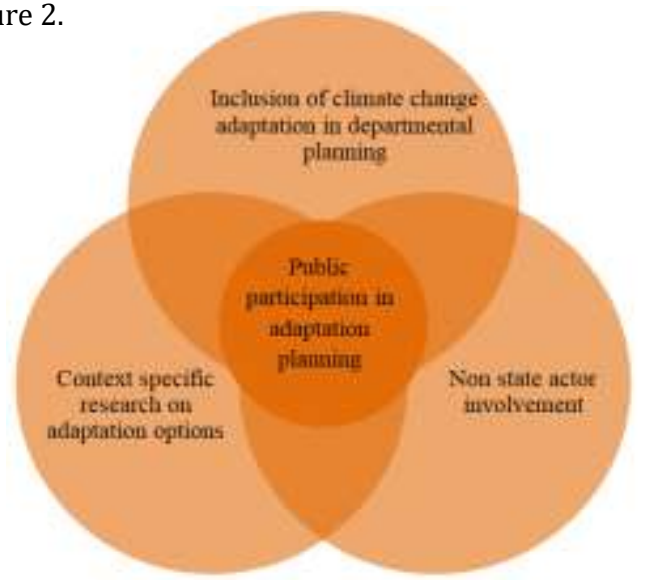

FIGURE 2: Proposed integrated approach to adaptation planning 


\section{CONCLUSION}

Adaptation is essential in order to protect and improve livelihoods against the impacts of climate change. As such adaptation actions are important for the achievement of Sustainable Development Goals on Climate Action and Zero Hunger, as climate change has largely impacted agriculture resulting in food insecurity. Adaptation strategies need to be holistically planned through an integrated approach. There is also need for adaptive capacity assessment at local level as it cannot be assumed that current adaptation strategies are a one size fits all. Comprehensive and inclusive assessments enable better targeting and also acceptance of interventions by the intended beneficiaries.

\section{REFERENCES}

[1] Allen, M.; Antwi-Agyei, P.; Aragon-Durand, F.; Babiker M.; Bertoldi, P.; Bind, M.; Brown, S.; Buckeridge, M.; Camilloni, I.; Cartwright, A., Technical Summary: Global warming of $1.5^{\circ} \mathrm{C}$. An IPCC Special Report on the impacts of global warming of $1.5^{\circ} \mathrm{C}$ above preindustrial levels and related global greenhouse gas emission pathways, in the context of strengthening the global response to the threat of climate change, sustainable development, and efforts to eradicate poverty. 2019.

[2] McMichael, A. J.; Woodruff, R. E.; Hales, S. J. T. L., Climate change and human health: present and future risks. 2006, 367 (9513), 859-869.

[3] Dejene, A.; Midgley, S.; Marake, M. V.; Ramasamy, S., Strengthening capacity for climate change adaptation in agriculture: experiences and lessons from Lesotho. FAO: 2011.

[4] De Chavez, T.-C.; Tauli-Corpus, D., Guide to climate change. 2008.

[5] IPCC, Climate change 2007: impacts, adaptation and vulnerability. 2007.

[6] Murray, V.; Ebi, K. L., IPCC special report on managing the risks of extreme events and disasters to advance climate change adaptation (SREX). BMJ Publishing Group Ltd: 2012.

[7] Brooks, N.; Neil Adger, W.; Mick Kelly, P., The determinants of vulnerability and adaptive capacity at the national level and the implications for adaptation. Global Environmental Change 2005, 15 (2), 151-163.

[8] Lemos, M. C.; Agrawal, A.; Eakin, H.; Nelson, D. R.; Engle, N. L.; Johns, O., Building adaptive capacity to climate change in less developed countries. In Climate science for serving society, Springer: 2013; pp 437-457.

[9] Ringler, C.; Zhu, T.; Cai, X.; Koo, J.; Wang, D. J. I. f. C. C. C. S., Climate change impacts on food security in subSaharan Africa. 2010, 2.

[10] BOS, Lesotho 2016 Census report. statistics, B. o., Ed. Government printing: Maseru, 2018.

[11] Mapfumo, P.; Thabane, K.; Mtimuni, A.; Nkondze, M.; Mumba, A.; Lindiwe Majela Sibanda, D., Evidence to support climate change adaptation in Lesotho, Malawi and Swaziland. 2015.

[12] McCarthy, J. J.; Canziani, O. F.; Leary, N. A.; Dokken, D. J.; White, K. S., Climate change 2001: impacts, adaptation, and vulnerability: contribution of Working Group II to the third assessment report of the Intergovernmental Panel on Climate Change. Cambridge University Press: 2001; Vol. 2.

[13] WFP Improving adaptive capacity of vulnerable and food insecure population in Lesotho; World Food Programme: 2019.

[14] Gwimbi, P.; Hachigonta, S.; Lindiwe Majela Sibanda, D., Southern African Agriculture and Climate Change: A Comprehensive Analysis-Lesotho. 2012.

[15] IFAD, Lesotho COSOP 2020-2025. https://www.ifad.org/en/-/document/lesotho-cosop2020-2025 (accessed 28/April/2021).

[16] LMS, Lesotho's Nationally Determined Contributions (NDC). Meteorology, M. o. E. a., Ed. Lesotho, 2017.

[17] Amusan, L.; Olutola, O. J. E. e., Climate change, complex interdependence and development: assessment of Lesotho-South Africa relations. 2015, (6, Iss. 4 (contin.)), 123-132.

[18] Morahanye, M. Role of Non-Governmental Organizations (NGOs) in climate change adaptation and mitigation strategies: a case study on Leribe district, Lesotho. University of the Free State, 2020.

[19] Ziervogel, G. J. G. J., Targeting seasonal climate forecasts for integration into household level decisions: the case of smallholder farmers in Lesotho. 2004, 170 (1), 6-21.

[20] LVAC, Lesotho Vulnerability Assessment Country Annual Assessment Report. Lesotho Vulnerability Assessment Committee: Lesotho, 2018.

[21] Molaoa, T. Social resilience to climate change in Lesotho. University of the Free State, 2016.

[22] Gwimbi, P. J. I. J. o. C. C. S.; Management, Mainstreaming national adaptation programmes of action into national development plans in Lesotho. 2017.

[23] LMS, Lesotho's National Adaptation Programme of Action on Climate Change. Lesotho Metereological Services: Lesotho, 2007.

[24] Drimie, S.; Gillespie, S. J. e. s.; policy, Adaptation to climate change in Southern Africa: factoring in AIDS. 2010, 13 (8), 778-784.

[25] LMS, National Climate Change Policy-2017-2027. GoL, Ed. Maseru, 2017.

[26] Hlalele, B. M. Vulnerability assessment of agricultural drought hazard: a case of Koti-Se-Phola community council, Thabana Morena, Mafeteng district in Lesotho. University of the Free State, 2014.

[27] LVAC, Annual Vulnerability Assessment and Analysis report. Lesotho, 2016.

[28] WFP Integrated Context Analysis: LESOTHO. https://geonode.wfp.org/documents/6917/download.

[29] WFP Emergency assistance for vulnerable households affected by El Niño drought conditions in Lesotho https://www.wfp.org/operations/200939emergency-assistance-vulnerable-householdsaffected-el-nino-drought-conditions. 
[30] Sekaleli, T. S. T.; Sebusi, K., Farmers' response and adaptation strategies to climate change in Mafeteng district, Lesotho. 2013.

[31] Mekbib, S. B.; Olaleye, A. O.; Mokhothu, M. N.; Johane, M.; Tlali, S. B.; Godeto, T. W., Assessment on the adaptive capacity of the Machobane farming system to climate change in Lesotho. 2011.

[32] Muroyiwa, B.; Ts'elisang, L. T. J. J. o. A.; Development, R., FACTORS AFFECTING FOOD SECURITY OF RURAL FARMERS IN LESOTHO: THE CASE OF KEYHOLE GARDENERS IN LERIBE DISTRICT. 2021, 59 (1), 77-90.

[33] FAO, Agriculture and Nutrition: Lessons from the field and good practices. In Keyhole gardens in Lesotho for better nutrition and livelihoods, FAO: Rome, 2013.

[34] Bank., W. Climate-Smart Agriculture in Lesotho. CSA Country Profiles for Africa Series.; Washington, D.C., 2018.; p 28

[35] Silici, L., Conservation agriculture and sustainable crop intensification in Lesotho. Food and Agriculture Organization of the United Nations (FAO): 2010; Vol. 10
[36] FAO, Conservation Agriculture: Food security in Lesotho for a changing climate. MAFS, Ed. 2012.

[37] Silici, L.; Ndabe, P.; Friedrich, T.; Kassam, A. J. I. j. o. a. s., Harnessing sustainability, resilience and productivity through conservation agriculture: the case of likoti in Lesotho. 2011, 9 (1), 137-144.

[38] Biesbroek, R.; Klostermann, J.; Termeer, C.; Kabat, P. J. C. l., Barriers to climate change adaptation in the Netherlands. 2011, 2 (2), 181-199.

[39] Conway, D.; Nicholls, R. J.; Brown, S.; Tebboth, M. G.; Adger, W. N.; Ahmad, B.; Biemans, H.; Crick, F.; Lutz, A. F.; De Campos, R. S. J. N. C. C., The need for bottomup assessments of climate risks and adaptation in climate-sensitive regions. 2019, 9 (7), 503-511.

[40] Jones, L.; Ludi, E.; Jeans, H.; Barihaihi, M. J. C.; Development, Revisiting the Local Adaptive Capacity framework: learning from the implementation of a research and programming framework in Africa. 2019, 11 (1), 3-13.

[41] Thabane, K.; Honu, B.; Paramiah, C. J. I. N. J., Determinants of Household-Level Vulnerability to Poverty in Mohale's Hoek District, Lesotho. 2014, 9, 1725. 